\title{
SINTESIS POLIOL LIGNIN ISOLAT DARI SERBUK KAYU JATI SEBAGAI BAHAN DASAR PEMBENTUKAN POLIURETAN DAN KARAKTERISASI MENGGUNAKAN FT-IR (FOURIER TRANSFORM INFRARED SPECTROSCOPY)
}

\author{
Supran Hidayat Sihotang \\ Dosen Prodi S1 Farmasi, STIKes Imelda, Jalan Bilal Nomor 52 Medan \\ Email : supran_hidayat@yahoo.com
}

\begin{abstract}
ABSTRAK
Telah disintesis poliuretan melalui sistem LI-PEG dengan Toluena Diisosianat (TDI). Lignin Isolat (LI) hasil isolasi serbuk kayu jati dimanfaatkan untuk sintesis poliuretan dengan cara memvariasikan LI-PEG dalam 10 gram. Lignin isolat sebagai poliol terlebih dahulu ditentukan bilangan hidroksinya dan dikarakterisasi melalui spektroskopi FT-IR yang menunjukkan bilangan gelombang pada daerah serapan $3448,72 \mathrm{~cm}^{-1}$ yang merupakan serapan khas dari rentangan $\mathrm{OH}$. Selanjutnya poliuretan yang terbentuk dikarakterisasi dengan FT-IR. Hasil yang diperoleh dalam penelitian ini dikonfirmasi dengan spektroskopi FT-IR, masing-masing spektrum FT-IR yang dihasilkan memberikan spektrum yang sesuai, terutama pada daerah panjang gelombang 3309,85 cm-1 merupakan serapan puncak gugus N-H, 2276,00 $\mathrm{cm}^{-1}$ merupakan puncak $C=O$ dari $N C O, 1381,03 \mathrm{~cm}^{-1}$ dan 1296,16 $\mathrm{cm}^{-1}$ merupakan puncak serapan $C-N$, $1219,01 \mathrm{~cm}^{-1}$ merupakan deformasi dari gugus $\mathrm{C}-\mathrm{O}$. Hal ini menunjukkan telah terbentukknya gugus uretan dari poliuretan.
\end{abstract}

Kata Kunci: Lignin, Poliuretan, Serbuk Kayu Jati, Toluena Diisosianat, Polietilena Glikol.

\section{PENDAHULUAN}

Poliuretan memiliki banyak manfaat, yaitu sebagai busa tempat tidur, sofa, asesoris mobil, serat, elastomer, dan pelapis (coating). Produk Poliuretan mempunyai bentuk yang beragam yaitu dari plastik elastomer linier lembut sampai busa termoset yang keras dan kaku. Sedangkan menurut Rohaeti,E. (2005) poliuretan dapat dijumpai pada berbagai bidang kehidupan. Di bidang otomotif, poliuretan dapat dijumpai sebagai komponen kendaraan yang meliputi bagian eksterior dan interior misalnya bumper, panel-panel body, dan tempat duduk. Di bidang kedokteran, poliuretan digunakan sebagai bahan pelindu ng muka, kantung darah, dan bahan tabung. Selain itu, poliuretan telah digunakan pula untuk furnitur, bangunan dan konstruksi, insulasi tank dan pipa, pabrik pelapis, alatalat olahraga, serta sebagai bahan pembungkus. Poliuretan diturunkan dari dua jenis lignin, yakni lignin kraft, lignosulfonat dan molase (Hatakeyama,H.2005).

Salah satu sumber yang memiliki potensi yang dapat menyamai kualitas bahan perekat sintetik yang banyak digunakan dipasaran adalah perekat yang bahan asalnya dari lignin. Lignin merupakan polimer alam yang mempunyai gugus hidroksil lebih dari satu dimanfaatkan sebagai sumber poliol yang akhirnya dapat/berikatan secara baik dengan poliuretan yang linear (supri, 2004). Lignin mempunyai sifat pertukaran ion karena adanya berbagai macam gugus fungsi yang membuatnya menjadi substansi yang sangat aktif (Rudnitskaya,A.2012). Carme (2008) telah membandingkan poliuretan berupa poliol yang berasal dari tumbuhan dengan poliol hasil sintesis dimana poliuretan yang poliol dari tumbuhan lebih mudah hancur karena terjadi penurunan berat molekul yang lebih rendah. Sedangkan Gryglewicz (2003) telah melakukan pembuatan neopentil glikol dan trimetilol propana sebagai poliol ester yang berasal dari tumbuhan dan lemak hewan dengan metode alkoholisis dimana dikarakterisasi dengan perbandingan kestabilan kondisi termal oksidasi yang lebih tinggi terhadap trigliserida dimana kestabilan kondisi termal oksidasi yang lebih tinggi bersal dari tumbuhan. Penentuan degradasi termal dari elastomer poliuretan didasarkan pada 4,4'dipenilmetan diisosianat dalam atmosfer 
nitrogen pada $600^{\circ} \mathrm{C}$ (Rosu,D.2010). Stabilitas termal antara lignin-hidroksi lebih baik daripada hanya menggunakan hidroksi saja pada pembuatan poliuretan (Sarkar,S.20 $01)$.

Dewasa ini penelitian tentang pemanfaatan lignin sebagai bahan dalam pembuatan perekat alam belum banyak menarik minat peneliti. Penelitian yang pernah dilakukan antara lain Interaksi perekat kayu dan fase morfologinya terhadap pembuatan perekat poliuretan (Ren,D.2012). Rozman,H.D. (2004) membu at poliuretan menggunakan MDI dan PEG dengan berat molekul 200. Tay, G.S. (2011) membuat poliuretan menggunakan poliol berbasis gliserol. Lase,E. (2009) mensintesis poliuretan melalui polimerisasi 4,4difenilme tana diisosianat dengan poliol dari minyak jarak pagar.

Berdasarkan dengan uraian diatas, maka dalam penelitian ini dimanfaatkan serbuk gergajian kayu jati, karena diperkirakan serbuk gergajian kayu jati tersebut mengandung lignin yang dapat diisolasi dengan menggunakan metode klason, dimana lignin merupakan polimer alam yang mempunyai lebih dari dua gugus hidroksi permolekulnya digunakan sebagai sumber poliol untuk sintesis poliuretan. Sehingga peneliti akan mensintesis poliuretan dengan mencampurkan lignin isolat dan Polietilen Glikol 1000 dengan memvariasikan jumlah lignin dan Polietilen Glikol 1000. Setelah terjadi campuran antara Lignin Isolat Polietilen Glikol (LI-PEG), maka akan direaksikan dengan Toluen diisosianat (TDI).

Kemudian diharapkan dalam penelitian ini penggunaan lignin isolat dari kayu jati yang ditambahkan Polietilen Glikol 1000 pada sintesis poliuretan dapat memperlihatk an karakteristik yang dihasilkan, sehingga dapat memberikan informasi dan manfaat dalam bidang industri.

\section{Rumusan Masalah}

Rumusan masalah pada peneltian ini adalah Apakah poliuretan dapat disintesis melalui polimerisasi Toluena diisosianat
(TDI) dengan lignin yang diperoleh dari serbuk kayu jati dan penambahan Polietil en Glikol 1000 (PEG 1000) dan bagaima na perbandingan campuran lignin dari se rbuk kayu jati dengan Polietilen Glikol 1 000 (PEG 1000) untuk mensintesis poliuretan.

\section{Tujuan Penelitian}

Untuk mengetahui sintesis poliureta $\mathrm{n}$ melalui polimerisasi Toluena diisosian at (TDI) dengan lignin yang diperoleh dari serbuk kayu jati dan penambahan Polietilen Glikol 1000 (PEG 1000) dan Untuk mengetahui perbandingan campur an lignin dari serbuk kayu jati dengan Polietilen Glikol 1000 (PEG 1000) untuk mensintesis poliuretan.

\section{Manfaat Penelitian}

Melalui hasil penelitian ini diharapk an dapat bermanfaat :

1. Sebagai salah satu cara meningkatka n pemanfaatan hasil dari serbuk gergajian kayu jati.

2. Sebagai informasi bahwa kayu jati dapat digunakan sebagai sumber lignin dalam sintesis poliuretan yang dapat meningkatkan nilai tambah didalam industri.

\section{METODE \\ Bahan-bahan}

Bahan-bahan yang digunakan dalam penelitian ini adalah serbuk kayu jati diperoleh dari toko panglong Citra Jaya Medan-Sumatera Utara, Toluena diisosianat, benzena, asam sulfat, etanol, $\mathrm{NaOH}$, asam asetat anhidrat, piridin.

\section{Alat-alat}

Alat-alat yang dipergunakan berupa alat-alat kaca yang biasa dipergunakan di laboratorium, alat-alat gelas, mixer, neraca analitis, ayakan $80 \mathrm{mesh}$, seperangkat alat Fourier Transform Infrared Spectroscopy (FT-IR). 


\section{Cara Kerja}

\section{Preparasi Lignin Isolat dari Serbuk Kayu Jati}

Serbuk kayu jati dikeringkan dan digiling, hasil gilingan dalam bentuk serbuk dengan ukuran 80 mesh. Ekstraksi dan isolasi dilakukan dengan menggunakan metoda Klason. Prosedur metoda Klason adalah :

a. Menimbang $1 \pm 0,1$ gram contoh kayu.

b. Mengekstraksi contoh kayu dengan etanol : benzena dengan perbandingan 1:2 selama 8 jam. Kemudian dicuci dengan etanol dan air panas lalu dikeringkan dalam oven pada suhu $105^{\circ} \mathrm{C}$.

c. Memindahkan contoh kayu kedalam gelas piala $100 \mathrm{ml}$ dan menambahkan asam sulfat $72 \%$ sebanyak $15 \mathrm{ml}$. Penambahan dilakukan secara perlahanlahan di dalam bak perendaman sambil dilakukan pengadukan dengan batang pengaduk selama 2-3 menit.

d. Setelah terdispersi sempurna, menutup gelas piala dengan kaca arloji dan dibiarkan pada bak perendaman selama 45 menit dan sekali-kali dilakukan pengadukan.

e. Aqudest sebanyak 300-400 ml dimasukkan ke dalam Erlenmeyer 1000 $\mathrm{ml}$ dan contoh dipindahkan dari gelas piala secara kuantitatif. Kemudian larutan diencerkan dengan aquadest samapai volume $575 \mathrm{ml}$ sehingga konsentrasi $\mathrm{H}_{2} \mathrm{SO}_{4} 3 \%$.

f. Larutan dipanaskan sampai mendidih dan dibiarkan selama 1 jam dengan pemanasan tetap dan dapat digunakan pendingin balik.

g. Kemudian membiarkanya sampai endapan lignin mengendap sempurna.

h. Larutan didekantasi dan endapan lignin dipindahkan secara kuantitatif kecawan atau kertas saring yang telah diketahui beratnya.

i. Endapan lignin dicuci sampai bebas asam dengan aquadest panas, kemudian diuji dengan kertas $\mathrm{pH}$ universal.

j. Cawan masir atau kertas saring beserta endapan lignin dikeringkan dalam oven dengan suhu $105^{\circ} \mathrm{C}$. k. Untuk cara ini rendemen lignin dihitung dengan persamaan 1 dibawah ini

Rendemen Lignin $=$

$\frac{\text { Berat Lignin }}{\text { Berat kayu kering }} \times 100 \%$

\section{Kadar Kemurnian Lignin (Metoda Klason)}

Ke dalam gelas piala ukuran $100 \mathrm{ml}$ dimasukkan sebanyak 0,5 gram lignin yang telah dikeringkan dalam oven pada suhu $105^{\circ} \mathrm{C}$ selama 4 jam. Kemudian dilarutkan dengan $15 \mathrm{ml} \mathrm{H}_{2} \mathrm{SO}_{4} 72 \%$ dengan perlahanlahan dan sambil diaduk dengan batang pengaduk selama 2-3 menit. Menutup dengan kaca arloji dan biarkan selama 2 jam. Hasil reaksi dipindahkan dalam labu erlenmeyer ukuran $500 \mathrm{ml}$. Diencerkan dengan aquadest sampai $400 \mathrm{ml}$, lalu direfluks selama 4 jam. Endapan lignin yang terbentuk disaring dengan kaca masir yang terlebih dahulu ditentukan beratnya dan dicuci dengan aquadest sampai bebas asam. Sampel dikeringkan dalam oven pada suhu $105^{\circ} \mathrm{C}$ dan ditimbang sampai berat konstan, kadar kemurnian lignin dapat dihitung dengan persamaan 2 dibawah ini ;

Kadar Lignin $=\frac{\text { Berat Sampel }}{\text { Berat kering lignin }} \times 100 \%$

\section{Penentuan Bilangan Hidrosi Pada Lignin \\ Analisis ini dilakukan terhadap isolat} lignin yang diisolasi dari kayu jati. Adapun cara kerja penentuan bilangan hidroksi adalah sebagai berikut:

a. Botol tahan tekanan dan panas disiapkan seperlunya untuk penentuan blanko dan sampel.

b. Dipipet $20 \mathrm{ml}$ reagent asetilasi yang dibuat dengan mencampurkan $127 \mathrm{ml}$ asam asetat anhidrat dengan $1000 \mathrm{ml}$ piridin.

c. Dua buah botol disiapkan untuk penentuan blanko dan kedalam botol lain dimasukkan sejumlah sampel sebanyak 1 gram.

d. Botol-botol tersebut ditutup dan dikocok hingga sampel tersebut larut.

e. Masing-masing botol diletakkan pada posisi yang sesuai dalam penangas 
minyak pada suhu $98^{\circ} \mathrm{C}$ selama 1 jam (diusahakan minyak yang ditambahkan dalam bath sesuai dengan tinggi permukaan larutan dalam botol.

f. Botol - botol tersebut dikeluarkan dari bath dan dibiarkan hingga botol-botol itu dingin pada temperatur kamar.

g. Bilas dengan hati-hati larutan pada penutup botol, dibilas pada dinding flask, sekitas $10-15 \mathrm{ml}$ aquadest.

h. Pada masing-masing botol ditambahkan potongan es yang bersih hingga sekitar setengahnya.

i. Setelah selesai didinginkan, tambahkan 2-3 tetes larutan indikator PP dan dititrasi segera dengan larutan $\mathrm{NaOH}$ yang terlebih dahulu distandarisasi hingga titik akhir titrasi yang ditandai oleh larutan berwarna pink.

j. Mencatat volume $\mathrm{NaOH}$ yang digunakan pada titrasi.

Untuk menghitung jumlah $\mathrm{OH}$ dari suatu resin poliol dalam sampel mengikuti persamaan 3 dibawah ini;

$$
\text { Kandungan } \mathrm{OH}=\frac{(\mathrm{B}-\mathrm{A}) \mathrm{N}}{\mathrm{W}} \times 40
$$

\section{Pembuatan Poliuretan Dengan menggunakan Lignin Isolat Dari Serbuk Kayu Jati (Tectona Grandis L.f.)}

Sebanyak 10 gram Lignin Isolat dari serbuk kayu jati dimasukkan kedalam gelas beaker $250 \mathrm{~mL}$ lalu ditambahkan Toluena diisosianat sebanyak $20 \mathrm{~mL}$, campuran diaduk selama 15 menit pada suhu $40^{\circ} \mathrm{C}$. Campuran tersebut kemudian dimasukkan kedalam cetakan, dan ditempatkan kedalam Hot Compresor pada suhu $40^{\circ} \mathrm{C}$ selama 20 menit. Hasil cetakan didinginkan pada suhu kamar, kemudian dari cetakan tersebut dikeluarkan untuk di uji. Perlakuan yang sama juga dilakukan pada pencampuran TDI : PEG 1000 : Lignin dengan variasi perbandingan $(\mathrm{b} / \mathrm{b} / \mathrm{b}): 20: 10: 0 ; 20: 8,0: 2,0$ $20: 6,0 ; 4,0 ; 20: 4,0: 6,0 ; 20: 2,0: 8,0 ; 20: 0: 10$.

\section{Karakterisasi Poliuretan}

Hasil yang diperoleh kemudian dikarakterisasi untuk menentukan sifat-sifat termal dari poliuretan yaitu dengan Analisa gugus fungsi dengan uji Fourier Transform Infrared Spectroscopy (FT-IR), Analisa sifat morfologi permukaan dengan uji Scanning Electron Microscopy (SEM), Analisa sifat termal dengan uji Diffrential Scanning Calorimeter (DSC).

\section{HASIL}

Analisa Gugus Fungsi dengan Fourier Transform Infrared Spectroscopy

1. Analisa FT-IR Lignin Isolat Dari Serbuk Kayu Jati

Gambar 1. Spektrum FTIR Lignin Isolat dari Serbuk Kayu Jati

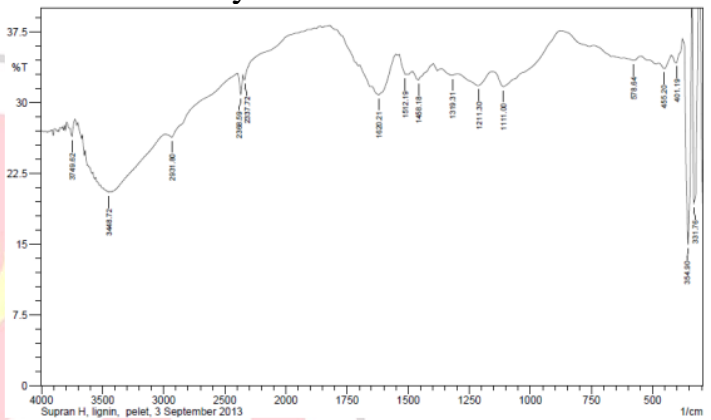

Analisa dengan spektrum infra merah ini dilakukan dengan cara mengamati frekuensi-frekuensi yang khas dari gugus fungsi spektra FTIR pada sampel lignin isolat. Hasil spektra FTIR yang dihasilkan dapat dilihat pada gambar 1. Bilangan gelombang FTIR lignin isolat dapat dilihat pada tabel 1 .

Tabel 1. Pita Serapan FTIR Lignin Isolat dari Kayu Serbuk Kayu Jati

\begin{tabular}{ccc}
\hline Sampel & $\begin{array}{c}\text { Kedudukan } \\
\left(\mathbf{c m}^{-1}\right)\end{array}$ & $\begin{array}{c}\text { Pita serapan } \\
\text { asal }\end{array}$ \\
\hline $\begin{array}{c}\text { Lignin } \\
\text { Isolat dari } \\
\text { Serbuk } \\
\text { Kayu Jati }\end{array}$ & $29450-3400$ & Rentangan OH \\
\cline { 2 - 3 } & $1715-1710$ & $\begin{array}{c}\text { Rentangan C=O } \\
\text { tak terkonjugasi }\end{array}$ \\
\hline & $1675-1660$ & $\begin{array}{c}\text { Rentangan C=O } \\
\text { terkonjugasi }\end{array}$ \\
\hline & $1605-1600$ & $\begin{array}{c}\text { Vibrasi cincin } \\
\text { aromatik }\end{array}$ \\
\hline $1515-1505$ & $\begin{array}{c}\text { Vibrasi cincin } \\
\text { aromatik }\end{array}$ \\
\hline $1470-1460$ & $\begin{array}{c}\text { Deformasi C-H } \\
\text { (asimetri) }\end{array}$ \\
\hline
\end{tabular}




\begin{tabular}{cc}
\hline $1430-1425$ & $\begin{array}{c}\text { Vibrasi cincin } \\
\text { aromatik }\end{array}$ \\
\hline $1330-1325$ & $\begin{array}{c}\text { Vibrasi cincin } \\
\text { siringil }\end{array}$ \\
\hline $1270-1275$ & $\begin{array}{c}\text { Vibrasi cincin } \\
\text { quaiasil }\end{array}$ \\
\hline $1085-1030$ & $\begin{array}{c}\text { Deformasi C-H } \\
\text { C-O }\end{array}$ \\
\hline
\end{tabular}

2. Analisa FTIR Pembuatan Poliuretan

Gambar 2. Spektrum FTIR Poliuretan Pada Perbandingan TDI $:$ PEG $1000:$ LIGNIN $=$ 20:0:10

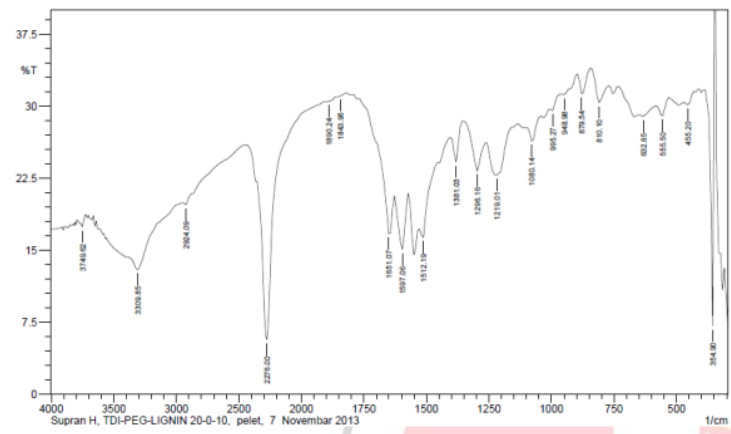

Gambar 3. Spektrum FTIR Poliuretan Pada Perbandingan TDI $:$ PEG $1000:$ LIGNIN = $20: 4,0: 6,0$

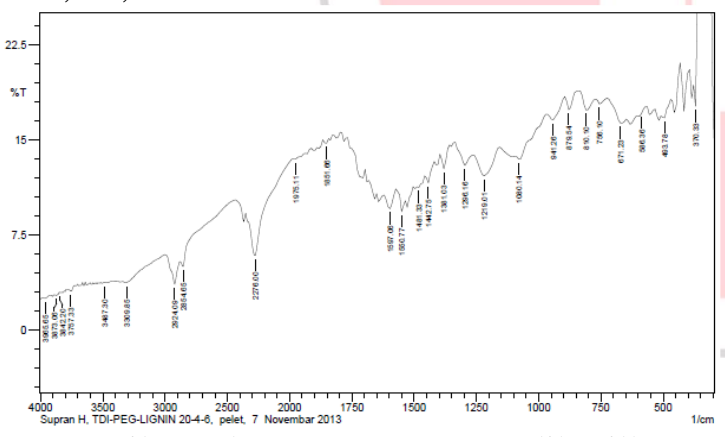

Hasil spektra FTIR yang dihasilkan pada pembuatan poliuretan pada gambar 2 dan dan gambar 3 dapat dilihat bilangan gelombang FTIR pada tabel 2.

Tabel 2. Pita Serapan FTIR Poliuretan

\begin{tabular}{ccc}
\hline Sampel & $\begin{array}{c}\text { Kedudukan } \\
\left(\mathbf{c m}^{-1}\right)\end{array}$ & $\begin{array}{c}\text { Pita serapan } \\
\text { asal }\end{array}$ \\
\hline \multirow{2}{*}{ Poliuretan } & $3295-3280$ & $\begin{array}{c}\text { Gugus N-H } \\
\text { terikat }\end{array}$ \\
\cline { 2 - 3 } & $2940-2820$ & $\begin{array}{c}\text { Rentangan metil } \\
\text { dan metilen }\end{array}$ \\
\hline & $1715-1710$ & $\begin{array}{c}\text { Rentangan C=O } \\
\text { tak terkonjugasi }\end{array}$ \\
\hline
\end{tabular}

\begin{tabular}{cc}
\hline $1675-1660$ & $\begin{array}{c}\text { Rentangan C=O } \\
\text { terkonjugasi }\end{array}$ \\
\hline $1605-1600$ & $\begin{array}{c}\text { Vibrasi cincin } \\
\text { aromatik }\end{array}$ \\
\hline $1515-1505$ & $\begin{array}{c}\text { Gugus amida } \\
\text { CO-NR }\end{array}$ \\
\hline $1470-1460$ & $\begin{array}{c}\text { Deformasi C-H } \\
\text { asimetri) }\end{array}$ \\
\hline $1430-1425$ & $\begin{array}{c}\text { Vibrasi cincin } \\
\text { aromatik }\end{array}$ \\
\hline $1330-1325$ & $\begin{array}{c}\text { Vibrasi cincin } \\
\text { siringil }\end{array}$ \\
\hline $1270-1275$ & $\begin{array}{c}\text { Vibrasi cincin } \\
\text { quaiasil }\end{array}$ \\
\hline $1085-1030$ & $\begin{array}{c}\text { Deformasi C-H } \\
\text { C-O }\end{array}$ \\
\hline
\end{tabular}

Hasil karakterisasi terhadap poliuretan hasil sintesis dari reaksi polimerisasi TDI : PEG 1000 : LIGNIN pada semua perbandingan menunjukkan pita serapan pada daerah yang hampir sama terutama pada daerah pita serapan karakteristik. Spektrum polimerisasi poliuretan pada perbandingan TDI : PEG $1000:$ LIGNIN = 20:0 : 10 (gambar 2) menunjukkan spektrum yang paling optimum. Sedangkan Spektrum polimerisasi poliuretan pada perbandingan TDI : PEG $1000:$ LIGNIN = $20: 4,0: 6,0$ (gambar 3) menunjukkan spektrum yang paling minimum dibanding spektrum yang lainnya.

\section{KESIMPULAN}

Dari hasil penelitian yang telah dilakukan mengenai pembuatan poliuretan alam melalui polimerisasi Toluena diisosianat (TDI) dengan Lignin Isolat dari serbuk kayu jati (Tectona Grandis L.f) dan Polietilen glikol, maka dapat diambil kesimpulan sebagai berikut : Lignin isolat hasil isolasi dari serbuk kayu jati (Tectona Grandis L.f) memiliki rendemen $23,84 \%$, kemurnian lignin sebesar $86 \%$ dan memiliki bilangan hidroksi $560 \mathrm{mmol} / \mathrm{gr}$.

Spektrum polimerisasi poliuretan pada perbandingan TDI $:$ PEG $1000:$ LIGNIN = $20: 0: 10$ menunjukkan spektrum yang paling optimum, sedangkan Spektrum polimerisasi poliuretan pada perbandingan TDI $:$ PEG $1000:$ LIGNIN = $20: 4,0: 6,0$ menunjukkan spektrum yang paling minimum dibanding spektrum yang lainnya. 


\section{SARAN}

Diharapkan untuk penelitian selanjutny a pada pembuatan poliuretan menggunakan poliol alam dari serbuk kayu jati menggunakan katalisator serta surfaktan untuk mempercepat reaksi pembentukan poliuretannya sehinga menghasilkan sifatsifat yang baik, dan dapat dilakukannya karakterisasi lanjutan untuk hasil yang lebih jelas.

\section{DAFTAR PUSTAKA}

Carme, M. (2008). Characterisation Of Polyurethane Networks Based On Vegetable Derived Polyol. Polymer, 49, 3279-3287.

Gryglewicz, S. (2003). Preparation Of Polyol Esters Based On Vegetable And Animal Fats. Bioresource Technology, 87, 35-39.

Hatakeyama, H. (2005). Thermal And Mechanical Properties Of Polyurethane -Based Geocomposites Derived From Lignin And Molasses. Composites Part A: Applied Science And Manufacturing, 36, 698-704.

Lase, E. (2009). Sintesis Poliuretan Melalui Polimerisasi 4,4-Difenilmetana Diisosianat Dengan Senyawa Poliol Yang Diturunkan Dari Minyak Jarak Pagar (Jatropa Curcas Linn). Tesis. Medan : Universitas Sumatera Utara.

Ren, D. (2012). Wood/Adhesive Interactions And The Phase Morphology of Moisture-Cure Polyurethane Wood Adhesives. International Journal of Adhesion \& Adhesives, 34, 55-61.
Rohaeti, E. (2005). Kajian Tentang SintesisPoliuretan dan Karakterisasiny a. Yogyakarta : Fakultas Matematika dan Ilmu Pengetahuan Alam Universita s Negeri Yogyakarta.

Rosu, D. (2010). Investigations On The Thermal Stability Of a MDI Based Polyurethane Elastomer. Journal of Analytical and Applied Pyrolysis, 89, 152-158.

Rozman, H. D. (2004). Polyurethane (PU)Oil Palm Empty Fruit Bunch (EFB) Composites: The Effect Of EFBG Reinforcement In Mat Form And Isocyanate Treatment On The Mechani cal Properties. Polymer Testing, 23, 559-565.

Rudnitskaya, A. (2012). Electrochemical Impedance Study Of The LigninDerived Conducting Polymer. Electroc hemica Acta , 76, 69-76.

Sarkar, S. (2001). Thermal Stability Of Lignin-Hydroxy-Terminated Polybutadiene Copolyurethanes. Polym er Degradation and Stability, 73, 169175.

Supri. (2004). Kolerasi Daerah Hard dan Soft Segment dan Indeks Ikatan Hidrogen (HBI) Pada Struktur Poliureta n (PU) Dari Segmen Campuran Lignin Isolat-Polietilena Glikol. Jurnal Sains Kimia, Vol 8, No. 2, 48-49.

Tay, G. S. (2011). Polyurethane Composites Derived From Glyserol And Molasses Polyols Filled With Oil Palm Empty Fruit Bunches Studies By TG And DMA. Thermochimica Acta, 525, 190196. 